\title{
Fasudil preserves lung endothelial function and reduces pulmonary vascular remodeling in a rat model of end-stage pulmonary hypertension with left heart disease
}

\author{
RULIN ZHUANG ${ }^{1-3^{*}}$, JINFU WU $^{3,4^{*}}$, FANG LIN $^{1,2^{*}}$, LU HAN $^{1}$, XIAOTING LIANG ${ }^{1}$, \\ QINGSHU MENG ${ }^{1,2}$, YUYU JIANG ${ }^{1}$, ZHULIN WANG $^{3}$, AIXUE YUE $^{3}$, \\ YUYING GU ${ }^{5}$, HUIMIN FAN ${ }^{1-3}$, XIAOHUI ZHOU ${ }^{1,2}$ and ZHONGMIN LIU ${ }^{1-3}$

\begin{abstract}
${ }^{1}$ Research Center for Translational Medicine, ${ }^{2}$ Shanghai Heart Failure Research Center and ${ }^{3}$ Department of Cardiovascular Surgery, Shanghai East Hospital, Tongji University School of Medicine, Shanghai 200120; ${ }^{4}$ Department of Anesthesiology,

The First Affiliated Hospital of Zhengzhou University, Zhengzhou, Henan 450052; ${ }^{5}$ Department of Cardiology,
\end{abstract} \\ Shanghai East Hospital, Tongji University School of Medicine, Shanghai 200120, P.R. China
}

Received December 25, 2017; Accepted June 8, 2018

DOI: $10.3892 /$ ijmm.2018.3728

\begin{abstract}
Pulmonary hypertension (PH) due to left heart disease (LHD) is a common condition associated with significant morbidity. It contributes to the elevation of pulmonary vascular resistance and mean pulmonary pressure, eventually leading to heart failure and even mortality. The present study aimed to explore the potential efficacy of late and long-term treatment with a Rho-kinase (ROCK) signaling inhibitor, namely fasudil, in a rat model of end-stage PH-LHD. The PH-LHD model was established by supracoronary aortic banding, and the effect of fasudil treatment on the progression of PH-LHD was monitored. After 9 weeks (63 days) of supracoronary aortic banding, a significant increase in mean pulmonary pressure and RV systolic pressure was observed in the rats, associated with increased RhoA/ROCK activity in the lungs. Therapy with fasudil (30 mg/kg/day, intraperitoneal) for 4 weeks from postoperative day 35 reversed the hemodynamic disorder and prevented pulmonary vascular remodeling in rats with PH-LHD. In addition, the blockade of ROCK signaling by fasudil decreased the protein levels of endothelin-1 (ET-1)
\end{abstract}

Correspondence to: Professor Xiaohui Zhou, Shanghai Heart Failure Research Center, Shanghai East Hospital, Tongji University School of Medicine, 150 Jimo Road, 14-D2, Pudong, Shanghai 200120, P.R. China

E-mail: zxh100@tongji.edu.cn

Dr Zhongmin Liu, Department of Cardiovascular Surgery, Shanghai East Hospital, Tongji University School of Medicine, 150 Jimo Road, Shanghai 200120, P.R. China

E-mail: liu.zhongmin@tongji.edu.cn

${ }^{*}$ Contributed equally

Key words: pulmonary hypertension, left heart diseases, Rho/Rho-kinase, fasudil, endothelin-1 and the mRNA expression levels of endothelin A receptor and promoted the production of nitric oxide (NO) in rats with PH-LHD. Furthermore, fasudil inhibited the migration of human pulmonary microvascular endothelial cells and the proliferation of pulmonary artery smooth muscle cells induced by ET-1. Therefore, this late, long-term blockade of the ROCK pathway by fasudil may be a promising strategy to reverse hemodynamic dysfunction and impede the development of end-stage PH-LHD in patients.

\section{Introduction}

Pulmonary hypertension (PH) caused by left heart disease (LHD) affects over two thirds of patients with left ventricular (LV) dysfunction (1). PH-LHD is a common condition, contributing to the elevation of pulmonary vascular resistance (PVR) and mean pulmonary pressure, and eventually leading to heart failure and even mortality.

The pathogenesis of $\mathrm{PH}$ is complex and multifactorial, while vascular remodeling is considered to contribute to high PVR in PH. Endothelial dysfunction is the key triggering factor in the pathophysiology of pulmonary arterial hypertension (PAH). Although the etiologies are distinct, patients with $\mathrm{PH}$ are characterized by the progressive remodeling of the pulmonary vasculature and significant endothelial dysfunction (2). Despite advances in the therapy regimes for $\mathrm{PAH}$, which is generally defined as a different condition to PH-LHD owing to its distinct causes, no significant progress has been made in treatment strategies for PH-LHD. However, PH-LHD is a far more common type of $\mathrm{PH}$ in clinical settings. Although current medical therapies have shown certain beneficial effects in lowering the mortality rate of patients with $\mathrm{PH}$, these methods do not prevent the progression of remodeling of the pulmonary artery (3).

A number of previous studies have described the vital roles of RhoA (a small $\mathrm{G}$ protein) and its target and downstream effector, Rho-kinase (ROCK), in the pathogenesis of PH (4-9). In vascular walls, multiple cell types, including 
endothelial cells, smooth muscle cells and fibroblasts, maintain a homeostatic function and response to injury through the RhoA/ROCK pathway (10). Other studies, including our previous study, have demonstrated that the overexpression of ROCK serves a critical role in the pathogenesis of $\mathrm{PH}$ with distinct etiologies (4-9). In addition, ROCK signal inhibition has been reported to have beneficial effects in a range of $\mathrm{PH}$ animal models, such as in $\mathrm{PH}$ induced by monocrotaline, Sugen 5416/hypoxia, bleomycin or aortic banding (4-9). Previous studies have demonstrated that the expression and activity of ROCK are greatly increased in patients with idiopathic $\mathrm{PH}(1,11)$, and that its activity is closely correlated with the severity and duration of PH (1). Furthermore, results from several clinical trials have indicated the efficacy of inhibition of the ROCK signaling pathway by fasudil in patients with PH (12-14). In addition, long-term inhibition of the ROCK pathway can improve LV geometry and LV dysfunction in aortic-banded (15) and hypertension-sensitive rat models (16), as well as attenuate cardiac hypertrophy and fibrosis in mice with myocardial infarction (17). Recently, it was reported that fasudil attenuated PH-LHD in rats (9). However, the possible efficacy of a later and longer-term treatment with fasudil on established PH-LHD has yet to be fully elucidated.

In the present study, the aim was to evaluate the effects of 4-week fasudil treatment administered from postoperative day 35 on PH-LHD induced by supracoronary aortic banding in rats. The study also investigated whether fasudil exerts its activity in end-stage PH-LHD by protecting the function of endothelial cells.

\section{Materials and methods}

Animal maintenance. Specific-pathogen-free male juvenile Sprague-Dawley rats $(90 \pm 10$ g; 3-4 weeks old) were purchased from Shanghai SLAC Laboratory Animal Co., Ltd. (Shanghai, China). The animals were maintained in a 12-h light/dark cycle at $25^{\circ} \mathrm{C}$ and were provided free access to commercial rodent food and tap water prior to the experiments. All rats used in the experiments and all study protocols were approved by the Institutional Animal Care and Use Committee of Tongji University (Shanghai, China; date of application, April 15, 2016; approval no., TJLAC-015-033).

Experimental groups. A total of 52 rats were assigned to different groups at random. In the sham group $(n=9)$, a titanium clip was fixed at the mediastinal tissue beside the artery, serving as a control. As reported previously (18), PH-LHD was induced by banding the ascending aorta without further treatment in the $\mathrm{PH}$ group $(\mathrm{n}=14)$. In the $\mathrm{PH}+\mathrm{F}$ group $(\mathrm{n}=18)$, rats with induced PH-LHD were treated with fasudil $(30 \mathrm{mg} / \mathrm{kg} / \mathrm{day}$, intraperitoneal; cat. no., S1573; Selleck Chemicals, Houston, TX, USA) from day 35 after surgery, and treatment continued for 4 weeks. In the $\mathrm{F}$ group $(n=11)$, healthy rats were treated with fasudil without surgery.

Hemodynamic measurement and cardiac hypertrophy. At 9 weeks after the surgery, hemodynamic measurements were performed by cardiac catheterization, and the right ventricular (RV) systolic pressure (RVSP) and pulmonary artery pressure (PAP) were assessed by a polygraph system
(Power Lab 8/30; AD Instruments, Bella Vista, Australia) as previously described $(19,20)$. The animals were sacrificed on day 63 following the operation, and then the lung, RV and the combined $\mathrm{LV}$ and ventricular septal $(\mathrm{LV}+\mathrm{S})$ weights were measured. The lung tissues were also used to detect the protein expression of ROCK1, ROCK2 and endothelin-1 (ET-1), and the mRNA expression of ROCK1, ROCK2, RhoA, endothelin $A$ receptor (ETAR) and endothelin $B$ receptor (ETBR).

Tissue histopathology and immunofluorescence. Left lung and heart tissues were harvested and processed for hematoxylin and eosin (H\&E) staining, immunohistochemical (IHC) and wheat germ agglutinin (WGA) staining subsequent to being embedded in paraffin, cut into $3-\mu \mathrm{m}$ sections, picked up with slides and placed in an oven at $60^{\circ} \mathrm{C}$ for baking, and finally removed at a normal temperature. $\mathrm{H} \& \mathrm{E}$ staining was performed to assess arteriole muscularization and median wall thickness (MWT) in the lung sections. The lung tissue sections were stained with hematoxylin at room temperature for $5 \mathrm{~min}$. The slides were incubated in water at $25^{\circ} \mathrm{C}$ for $30 \mathrm{~min}$, dehydrated in $100 \%$ ethanol for $10 \mathrm{~min}$ three times, stained with eosin at room temperature for $5 \mathrm{~min}$ and then were dehydrated in $100 \%$ ethanol for $10 \mathrm{~min}$ three times, and mounted on cover slips. The slides were observed under a x200 magnification using a Nikon positive fluorescence microscope ECLIPSE $80 \mathrm{i}$ (Nikon Corporation, Tokyo, Japan). Five different fields of view were observed. The IHC assay was performed to evaluate the pulmonary vascular structural alterations with a monoclonal $\alpha$-smooth muscle actin ( $\alpha$-SMA) antibody (dilution, 1:200; cat. no. sc-32251; Santa Cruz Biotechnology, Inc., Dallas, TX, USA). Pulmonary distal arterioles were considered to be muscularized if $>75 \%$ of the circumference was $\alpha$-SMA-positive (magnification, $\mathrm{x} 400$ ). The MWT of the pulmonary artery was calculated with the Image-Pro Plus 6.0 software (Media Cybernetics, Inc., Rockville, MD, USA). IHC staining was also performed to evaluate the expression of ROCK1 (dilution, 1:200; cat. no. ab45171) and ROCK2 (dilution, 1:200; cat. no. ab125025; both purchased from Abcam, Cambridge, UK) in the left lung tissue samples.

In order to examine the cell size, WGA staining was performed, as previously described (21). Briefly, myocardial tissues were cut into $3-\mu \mathrm{m}$ sections and the slides were stained for $15 \mathrm{~min}$ with a WGA-FITC labeled antibody (dilution, 1:200; cat. no. W11261; Invitrogen; Thermo Fisher Scientific, Inc., Waltham, MA, USA) at room temperature subsequent to being fixed with $4 \%$ formaldehyde for $15 \mathrm{~min}$ at $37^{\circ} \mathrm{C}$, according to the manufacturer's protocol. Following labeling, the labeling solution was removed and the cells were washed twice in Hanks' Balanced Salt Solution. Then the cells were observed under a x400 magnification using a Nikon positive fluorescence microscope ECLIPSE 80i (Nikon Corporation). Five different fields of view were observed. Subsequently, the myocyte cross-sectional area of the left and right ventricles was measured using Image-Pro Plus 6.0 software.

Cell culture. Human pulmonary microvascular endothelial cells (HPMECs; cat. no., 3000) were purchased from ScienCell Research Laboratories, Inc. (San Diego, CA, USA), while human pulmonary artery smooth muscle cells (HPASMCs) were obtained from iCell Bioscience, Inc. (Shanghai, China). 
Table I. Quantitative polymerase chain reaction primers.

\begin{tabular}{lll}
\hline Gene & \multicolumn{1}{c}{ Forward primer $\left(5^{\prime}-3^{\prime}\right)$} & \multicolumn{1}{c}{ Reverse primer $\left(5^{\prime}-3^{\prime}\right)$} \\
\hline ROCK1 & ATTGAGCAGTTGCGTGCAAAA & TAAGGAATGCAGGCAGAACCA \\
ROCK2 & ACAAACCAAGCTAACTGCCT & ACGCGCATGTGGTGTATGTA \\
Rho kinase & CTGCGGGTACGAAGGTATCG & AGCATCCAATCCATCCAGCA \\
RhoA & ACCAGTTCCCAGAGGTGTATG & TTGGGACAGAAGTGCTTGACTTC \\
Endothelin A receptor & CCGAGGAGCTCTAAGGGGAA & CCAAAAGGACGCCAGAAAGC \\
Endothelin B receptor & AACCCGGCTAGGACTGAAAAC & AGAAGAGATGGTGTGGCCTG \\
GAPDH & GCCATCAACGACCCCTTCATTG & TGCCAGTGAGCTTCCCGTTC
\end{tabular}

ROCK, Rho-kinase.

All cells were cultured and subcultured according to the manufacturer's protocol. HPMECs were incubated in Endothelial Cell medium (ScienCell Research Laboratories, Inc.) and HPASMCs were maintained in Dulbecco's Modified Eagle's Medium and high glucose medium (Gibco; Thermo Fisher Scientific, Inc.) supplemented with $10 \%$ foetal bovine serum (FBS; Gibco; Thermo Fisher Scientific, Inc.) at $37^{\circ} \mathrm{C}$ under an atmosphere of $5 \% \mathrm{CO}_{2}$ and $95 \%$ air. Cells were used in the third passage at a concentration of $5 \times 10^{5}$ cells per well in a 12 well-plate, or $1 \times 10^{6}$ cells per well in a 6 -well plate. Cells were pre-stimulated with fasudil $(10 \mu \mathrm{M})$ for $2 \mathrm{~h}$, followed by incubation with ET-1 (10 nM; cat no. 1160; Tocris Bioscience, Bristol, UK) for a further $6 \mathrm{~h}$ for the migration assay. PBS-only treated cells were used as the control. HPMECs were used to confirmed the nitric oxide (NO) production and migration, while HPASMCs were used to detect the effect of fasudil on the proliferation of SMC.

Proliferation of HPASMCs. The proliferation of HPASMCs was assessed with a cell counting kit-8 (CCK-8; cat. no. 40203ES60; Yeasen, Shanghai, China) assay and Ki67 detection. Briefly, HPASMCs were plated in 96-well plates at a density of 5,000 cells/well. The cells received different treatments once they reached $50-60 \%$ confluence. CCK-8 solution $(10 \mu \mathrm{l})$ at a 1:10 dilution with FBS-free high glucose Dulbecco's modified Eagle's medium $(100 \mu \mathrm{l})$ was added to each well, followed by another $3 \mathrm{~h}$ of incubation at $37^{\circ} \mathrm{C}$. The absorbance was measured at $450 \mathrm{~nm}$ on a microplate reader (SpectraMax; Molecular Devices, LLC, San Jose, CA, USA). As previously described (22), viability of $>100 \%$ indicated cell proliferation, whereas viability of $<100 \%$ indicated cell death. In addition, cells were collected following stimulation, stained with the fluorophore-conjugated anti-Ki67 monoclonal antibody $(0.5 \mathrm{mg} / \mathrm{ml}$; dilution, 1:200; cat. no. 151204; BioLegend, Inc., San Diego, CA, USA) and then detected by FACS AriaII (BD Biosciences, Franklin Lakes, NJ, USA).

Migration of HPMECs. HPMECs were grown to confluence on 6-well plates in complete medium. Once confluence was reached, the cells were grown without FBS overnight and pre-stimulated with fasudil $(10 \mu \mathrm{M})$ for $2 \mathrm{~h}$. Next, a scratch was made down the center of the confluent monolayer with a 100- $\mu$ l pipette tip. After the scratch, $10 \mathrm{nM}$ ET- 1 was added, and images were captured at x40 magnification every $2 \mathrm{~h}$. The migration rate was determined by counting the number of cells that migrated into the wound. ImageJ software (National Institutes of Health, Bethesda, MD, USA) was used to quantify the results.

Detection of $m R N A$ levels by reverse transcription-quantitative polymerase chain reaction $(R T-q P C R)$. Total RNA was extracted from the tissues or cells using TRIzol (Thermo Fisher Scientific, Inc.) and the RNA concentration was measured using NanoDrop 2000 (Thermo Fisher Scientific, Inc.). The PrimeScript RT reagent kit (Takara Bio, Inc., Otsu, Japan) was then used to reverse transcribe $1 \mu \mathrm{g}$ RNA to cDNA. A Fast Real-Time PCR system (7900HT; Applied Biosystems; Thermo Fisher Scientific, Inc.) with SYBR Green MasterMix (Applied Biosystems; Thermo Fisher Scientific, Inc.) was subsequently used for qPCR. The thermocycling conditions were as follows: $96^{\circ} \mathrm{C}$ for $30 \mathrm{sec}, 57^{\circ} \mathrm{C}$ for $30 \mathrm{sec}$ and $72^{\circ} \mathrm{C}$ for $30 \mathrm{sec}$. The experiments were performed in triplicate for each sample. Relative quantification of mRNA was performed using the comparative threshold cycles (Cq) method. The mRNA expression level was measured using the $2^{-\Delta \Delta \mathrm{Cq}}$ method (23). Relative expression of each gene normalizing to GAPDH. All qPCR primers (including for ETAR and ETBR) used are listed in Table I.

NO and ET-1 serum concentration. ELISA kits were used to assess the concentration of NO (cat. no. G-7921; Molecular Probes; Thermo Fisher Scientific, Inc.) and ET-1 concentrations (cat. no. ADI-900-073; Enzo Life Sciences, Inc., Farmingdale, NY, USA) in the serum at day 63 post-operation prior to euthanasia.

$G$-LISA assay. The protein concentration of the lung lysates was evaluated by a bicinchoninic acid assay (cat. no. 23227; Pierce; Thermo Fisher Scientific, Inc.). RhoA activity was also determined in normalized lung lysates with a 96-well RhoA G-LISA Activation Assay kit (cat. no. BK124; Cytoskeleton, Inc., Denver, CO, USA). All assay procedures were conducted according to the manufacturer's protocol. The luminescence signal was quantified using a microplate reader.

Statistical analysis. All data are presented as the mean \pm standard error of the mean. Data were analyzed using SPSS software, version 11.0 (SPSS Inc., Chicago, IL, USA). For in vivo experiments, the Mann-Whitney $\mathrm{U}$ test was used for 
A

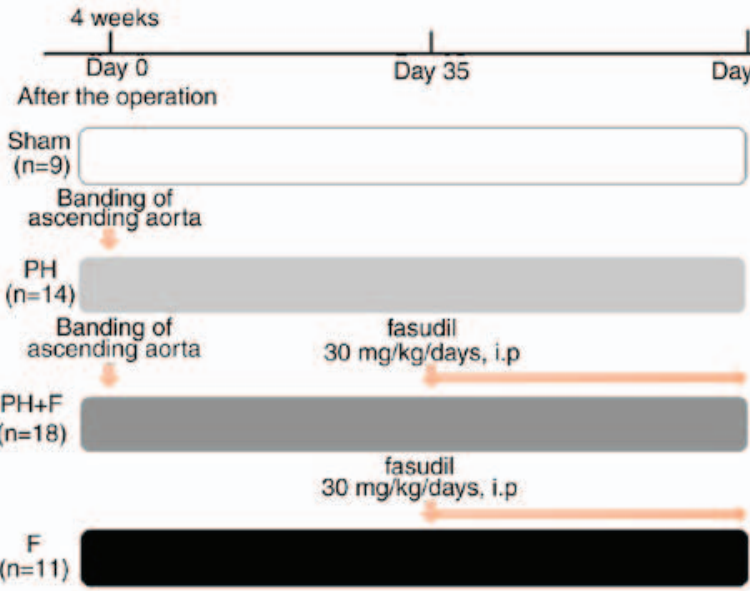

B Mean pulmonary arterial pressure

C Right ventricular systolic pressure
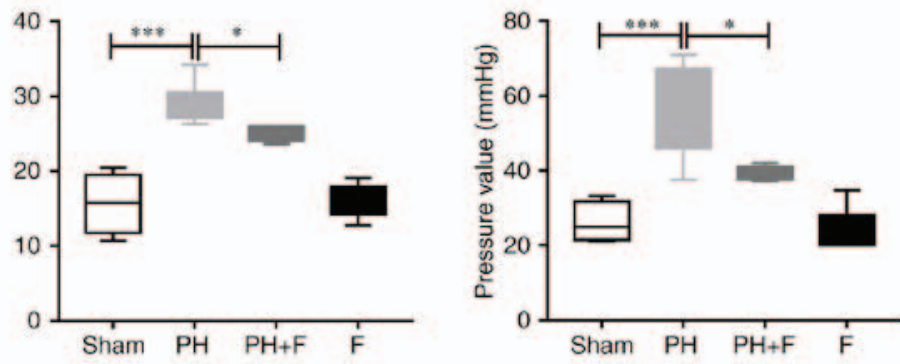

D Sham

$\mathrm{PH}$

$\mathrm{PH}+\mathrm{F}$

$\mathrm{F}$
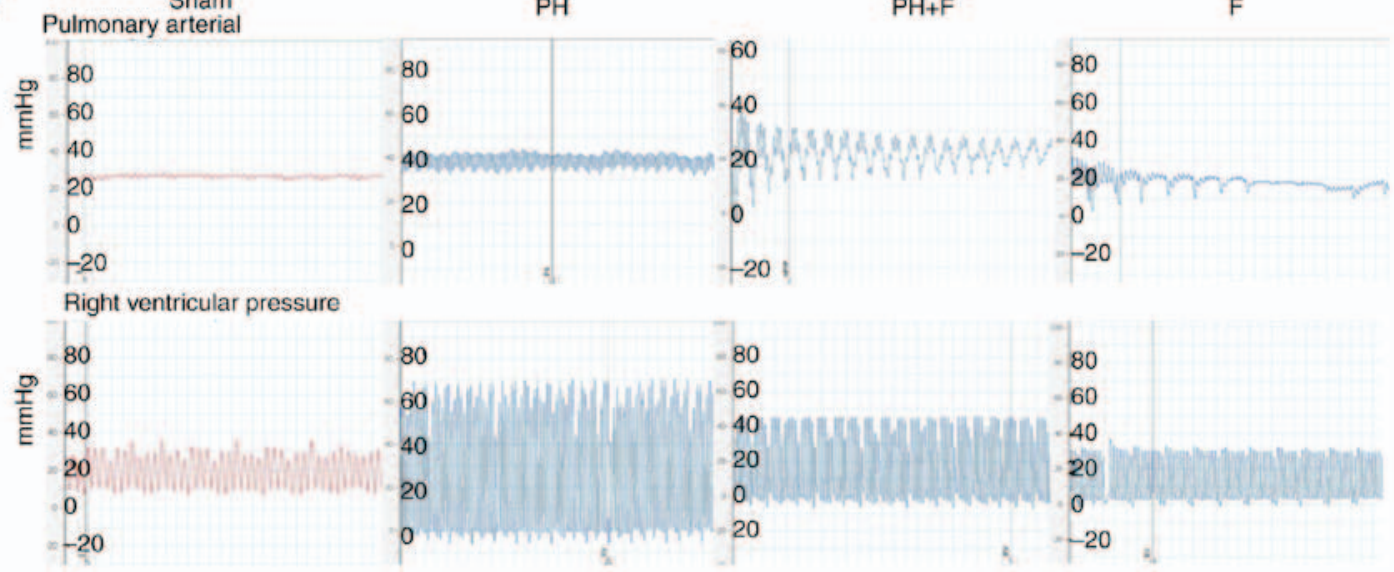

Figure 1. Experimental protocol and hemodynamic measurement of the mean PAP and RVSP values. (A) Design of the animal study. A total of 52 specific-pathogen-free male juvenile Sprague-Dawley rats were used in the study, and were randomly assigned to different groups. PH due to left heart disease was induced by banding the ascending aorta without further treatment in the $\mathrm{PH}$ group. The $\mathrm{PH}+\mathrm{F}$ group was additionally treated with $30 \mathrm{mg} / \mathrm{kg} / \mathrm{day}$ fasudil between days 35 and 63. In the F group, healthy rats were treated with fasudil without the banding surgery. Summarized (B) PAP and (C) RVSP data. (D) Representative figures of hemodynamic changes. $\mathrm{n}=9$ in Sham group, $\mathrm{n}=14$ in $\mathrm{PH}$ group, $\mathrm{n}=18$ in $\mathrm{PH}+\mathrm{F}$ group, and $\mathrm{n}=11$ in $\mathrm{F}$ group. " $\mathrm{P}<0.05$ and ${ }^{* * * *} \mathrm{P}<0.001$. PH, pulmonary hypertension; F, fasudil; PAP, pulmonary artery pressure; RVSP, right ventricular systolic pressure.

comparisons between different groups. One-way analysis of variance with a Bonferroni post-hoc test was used for multiple comparisons. $\mathrm{P}<0.05$ was considered to indicate a statistically significant difference.

\section{Results}

Fasudil downregulates the mean PAP in rats following supracoronary aortic banding. As reported previously (24), supracoronary aortic banding for 9 weeks led to a marked elevation in the mean PAP and RVSP in rats compared with that in the sham group $(\mathrm{P}<0.001$; Fig. 1$)$. To investigate whether fasudil treatment was able to reverse this elevation, rats were treated with fasudil $(30 \mathrm{mg} / \mathrm{kg} / \mathrm{day}$, intraperitoneal) for 4 weeks, commencing at day 35 after supracoronary aortic banding (Fig. 1A). The data revealed that fasudil treatment decreased the mean pulmonary pressure and the RVSP compared with those in the $\mathrm{PH}$ group (Fig. 1B-D; $\mathrm{P}<0.05$ ) at postoperative day 63. Compared with the sham group, there were no differences in either the mean PAP or RVSP when treated with fasudil alone in the $\mathrm{F}$ group.

Fasudil attenuates the ventricular hypertrophy in a rat PH-LHD model. The body weight (BW) of the rats in each 

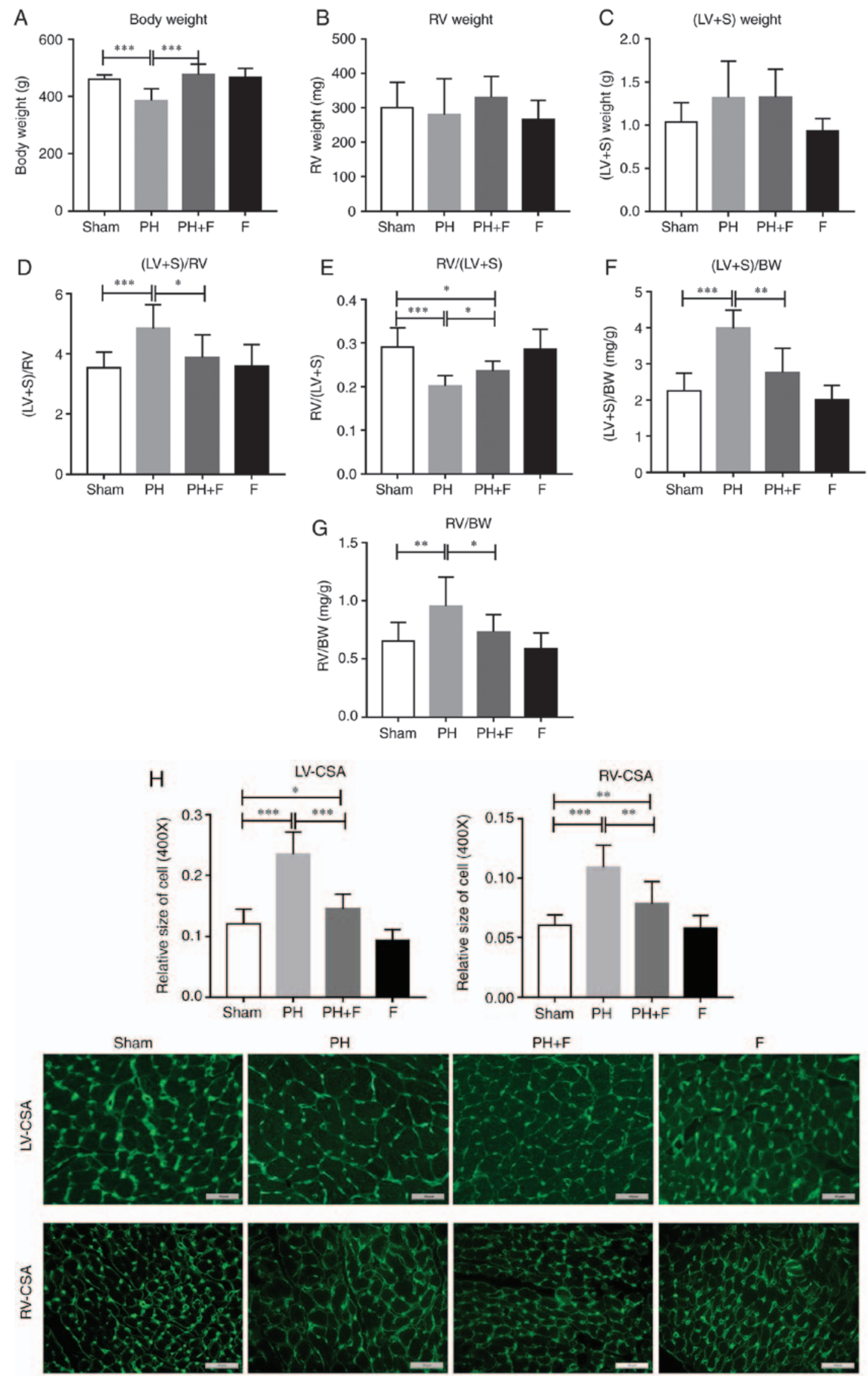

(Magnification, $\times 400)$

Figure 2. Effect of fasudil on BW and ventricular hypertrophy. (A) BW; (B) RV weight; and (C) LV+S weight. (D) (LV+S)/RV indicating LV hypertrophy. (E) $\mathrm{RV} /(\mathrm{LV}+\mathrm{S})$. (F) (LV+S)/BW ratios. (G) RV/BW ratios, indicating RV hypertrophy. (H) Wheat germ agglutinin staining conducted to evaluate the CSA of the left and right ventricles in the heart sections. Representative results from six different sections are shown ( $\mathrm{n}=9$ in Sham group, $\mathrm{n}=14$ in $\mathrm{PH}$ group, $\mathrm{n}=18$ in $\mathrm{PH}+\mathrm{F}$ group, and $\mathrm{n}=11$ in $\mathrm{F}$ group) (magnification, $\mathrm{x} 400$ ). ${ }^{*} \mathrm{P}<0.05,{ }^{* * *} \mathrm{P}<0.01$ and ${ }^{* * *} \mathrm{P}<0.001$. $\mathrm{PH}$, pulmonary hypertension; $\mathrm{F}$, fasudil; RV, right ventricular; LV, left ventricular; S, ventricular septal; CSA, myocyte cross-sectional area; BW, body weight. 
A Wall thickness/Vessel diameter

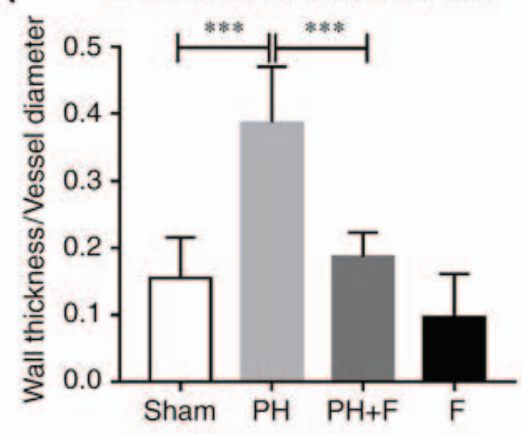

B

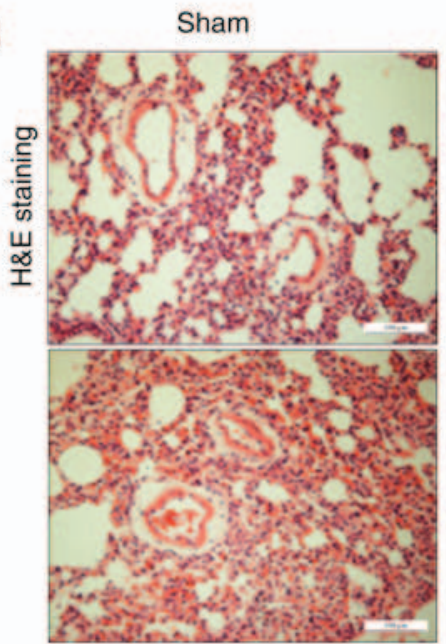

$\mathrm{PH}$

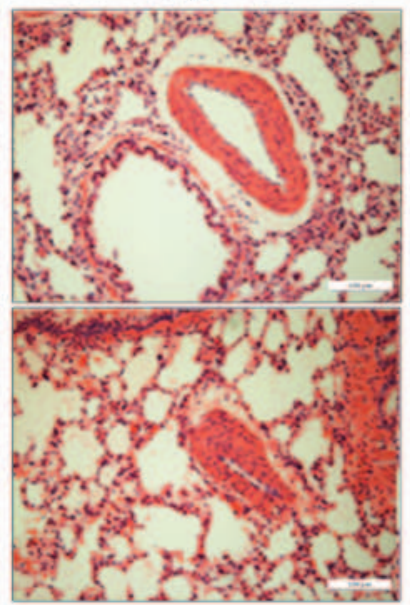

$\mathrm{PH}+\mathrm{F}$

$\mathrm{F}$
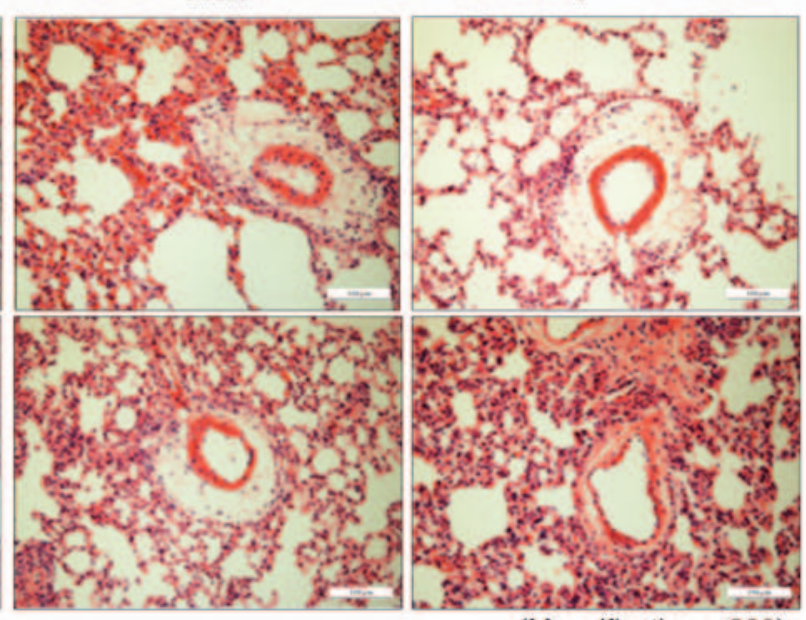

(Magnification, $\times 200$ )
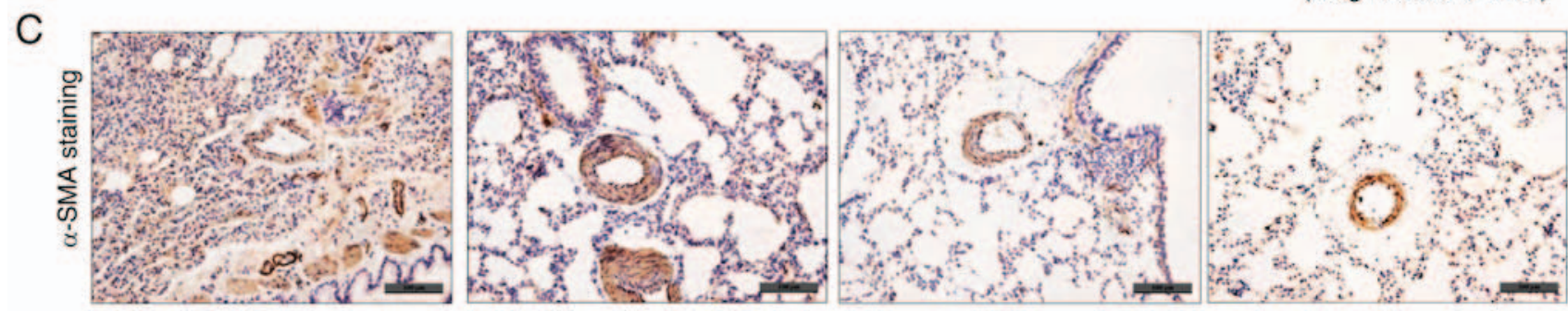

(Magnification, $\times 200$ )

Figure 3. Effect of fasudil on pulmonary vascular remodeling in a rat model of pulmonary hypertension due to left heart disease. (A) Summarized median wall thickness to vessel diameter ratios. (B) Representative images of lung sections with hematoxylin and eosin staining (magnification, x200). (C) Morphometric analysis of pulmonary vessels assessed by $\alpha$-SMA immunohistochemical staining (magnification, $\mathrm{x} 200$ ). Representative results from six different sections are shown ( $\mathrm{n}=9$ in Sham group, $\mathrm{n}=14$ in $\mathrm{PH}$ group, $\mathrm{n}=18$ in $\mathrm{PH}+\mathrm{F}$ group, and $\mathrm{n}=11$ in $\mathrm{F}$ group). ${ }^{* * *} \mathrm{P}<0.001$. $\mathrm{PH}$, pulmonary hypertension; $\mathrm{F}$, fasudil.

group were measured. After 9 weeks of aortic banding, the BW was significantly decreased as compared with that in the sham group $(\mathrm{P}<0.01$; Fig. $2 \mathrm{~A})$. Rats in the $\mathrm{PH}+\mathrm{F}$ group had significantly higher BW compared with those in the $\mathrm{PH}$ group $(\mathrm{P}<0.01)$. Furthermore, the $\mathrm{RV}$ and $\mathrm{LV}+\mathrm{S}$ weights were assessed to evaluate the hypertrophy of the left and right ventricles. As shown in Fig. 2B and C, there were no differences in the $\mathrm{RV}$ or $\mathrm{LV}+\mathrm{S}$ weight between the sham and $\mathrm{PH}$ groups. Notably, at day 63 , the ratio of $(\mathrm{LV}+\mathrm{S}) / \mathrm{RV}$ weight increased significantly ( $\mathrm{P}<0.01$; Fig. $2 \mathrm{D})$, while the $\mathrm{RV} /(\mathrm{LV}+\mathrm{S})$ ratio was markedly decreased $(\mathrm{P}<0.005$; Fig. $2 \mathrm{E}$ in rats with $\mathrm{PH}-\mathrm{LHD}$ as compared with the ratio in sham rats. Rats treated with fasudil also exhibited a reduction in $(\mathrm{LV}+\mathrm{S}) / \mathrm{RV}$ ratio (Fig. 2D). The ratios of ( $\mathrm{LV}+\mathrm{S}) / \mathrm{BW}$ and $\mathrm{RV} / \mathrm{BW}$ were further used to assess the extent of ventricular hypertrophy. A total of 9 weeks of supracoronary aortic banding increased the ratios of $(\mathrm{LV}+\mathrm{S}) / \mathrm{BW}$ and $\mathrm{RV} / \mathrm{BW}$, whereas treatment with fasudil reversed these elevated values (Fig. $2 \mathrm{~F}$ and G). These results suggested that hypertrophy occurred in the left and right ventricles at day 63 post-surgery, while LV hypertrophy was more pronounced than RV hypertrophy. WGA staining further confirmed that fasudil attenuated the myocyte hypertrophy of both the left and right ventricles in PH-LHD rats (Fig. 2H). As expected, there were no differences in the above indexes between the sham and $\mathrm{F}$ groups.

Fasudil prevents pulmonary vascular remodeling in rats with $P H-L H D$. To determine whether fasudil administration impeded pulmonary remodeling in rats with PH-LHD, arteriole muscularization and MWT were assessed in the lung sections. As displayed by $\mathrm{H} \& \mathrm{E}$ staining in Fig. 3A and $\mathrm{B}, 9$ weeks of supracoronary aortic banding resulted in an increase in MWT $(\mathrm{P}<0.01)$, whereas administration of fasudil markedly reduced MWT and muscularization. 
A
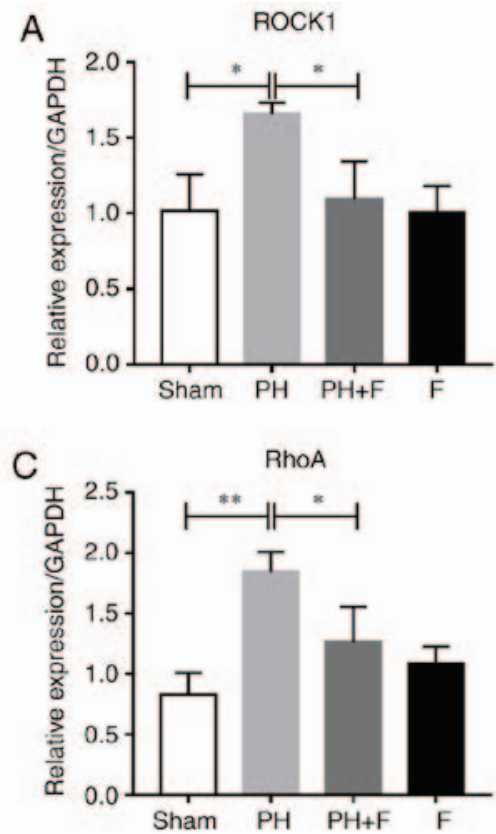

$\mathrm{E}$

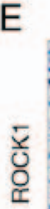

감

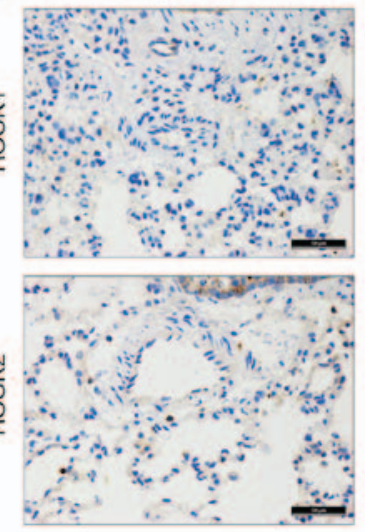

B

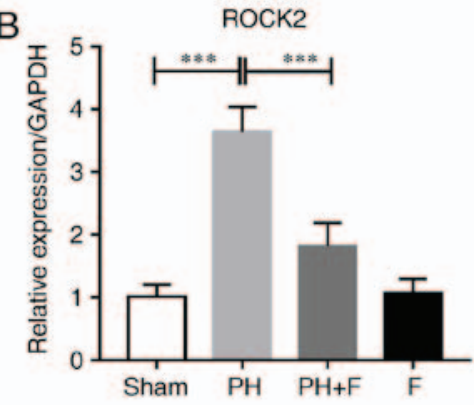

D

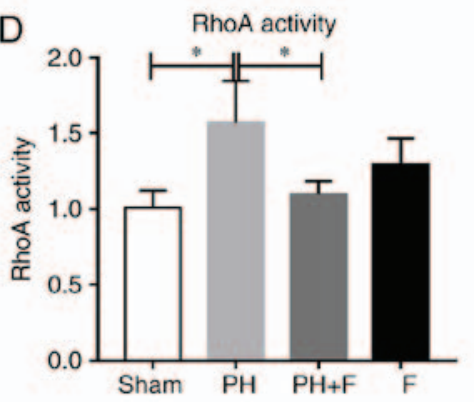

$\mathrm{PH}+\mathrm{F}$

F
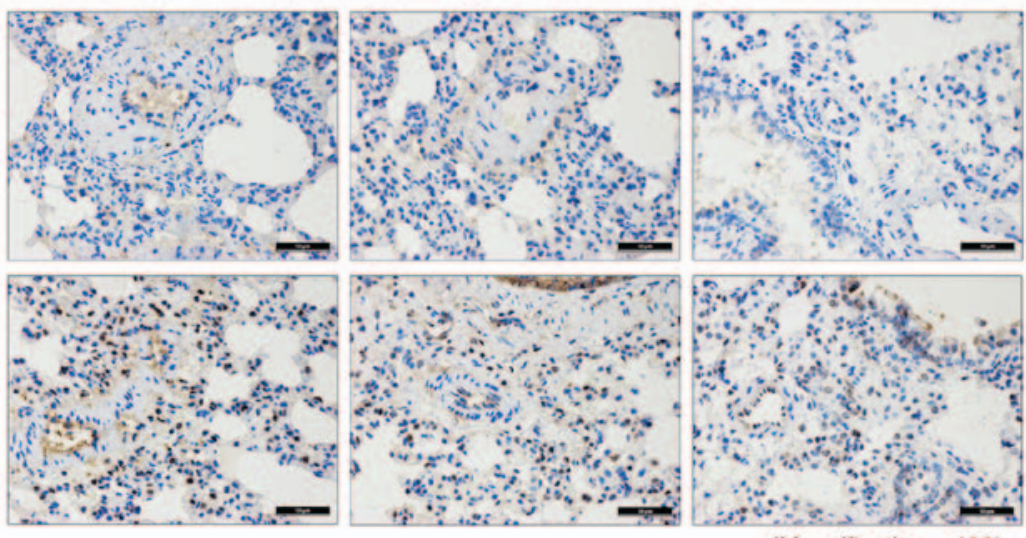

(Magnification, $\times 400$ )

Figure 4. Fasudil inhibited ROCK signaling in vivo. (A) ROCK1, (B) ROCK2 and (C) RhoA mRNA expression levels in lung tissues are shown. (D) RhoA activity in lung homogenates, as measured by a G-LISA RhoA activation assay. (E) Immunohistochemical staining results of ROCK1 and ROCK2 protein levels in lung tissues (magnification, $\mathrm{x} 400 ; \mathrm{n}=9$ rats in Sham group, $\mathrm{n}=14$ rats in $\mathrm{PH}$ group, $\mathrm{n}=18$ rats in $\mathrm{PH}+\mathrm{F}$ group, and $\mathrm{n}=11$ in $\mathrm{F}$ group). ${ }^{*} \mathrm{P}<0.05$, ${ }^{* * *} \mathrm{P}<0.01$ and ${ }^{* * *} \mathrm{P}<0.001$. $\mathrm{PH}$, pulmonary hypertension; F, fasudil; ROCK, Rho-kinase.

Compared with the sham group, there were no differences in MWT when treated with fasudil alone in the F group. Representative IHC images for $\alpha$-SMA are presented in Fig. 3C.

Inhibition of ROCK signaling by fasudil in rats with PH-LHD. To determine the efficacy of fasudil in vivo, the expression levels of ROCK1 and ROCK 2 was assessed in the lungs of rats in different groups. As shown in Fig. 4A and B, ROCK1 and ROCK2 mRNA levels were upregulated in the lungs of the PH group compared with the sham group, and fasudil treatment decreased the extent of this elevation. The RhoA mRNA level exhibited similar results (Fig. 4C). RhoA activity in the lung homogenates was also increased in the PH-LHD rats, and fasudil administration decreased the RhoA activity (Fig. 4D). There were no significant differences in the mRNA levels of ROCK1, ROCK2 and RhoA and the activity of RhoA between the sham and $\mathrm{F}$ groups. The IHC staining results further demonstrated that fasudil inhibited the upregulation of ROCK1 and ROCK2 protein levels by PH-LHD in the rat lungs (Fig. 4E).

Expression levels of ET-1 and ET-1 receptors in the rat model of $P H-L H D$. Previous studies have demonstrated that the severity of PH is associated with high ET-1 levels $(25,26)$. Thus, ET-1 levels were evaluated in the serum of rats. As shown in Fig. 5A, the ET-1 levels were significantly higher in the PH-LHD rats compared with that in the sham group, and the inhibition of ROCK signaling by fasudil reversed this elevation. Next, the mRNA levels of two ET-1 receptors (ETAR and ETBR) were detected. As shown in Fig. 5B, ETAR expression decreased in the $\mathrm{PH}+\mathrm{F}$ group compared with that in the $\mathrm{PH}$ group. By contrast, no significant differences in ETBR mRNA expression level were detected between groups (Fig. 5C).

Fasudil inhibits the migration of HPMECs and preserves lung endothelial function. Endothelial dysfunction is considered to be the key initiating factor in the pathophysiology of PAH (2). 

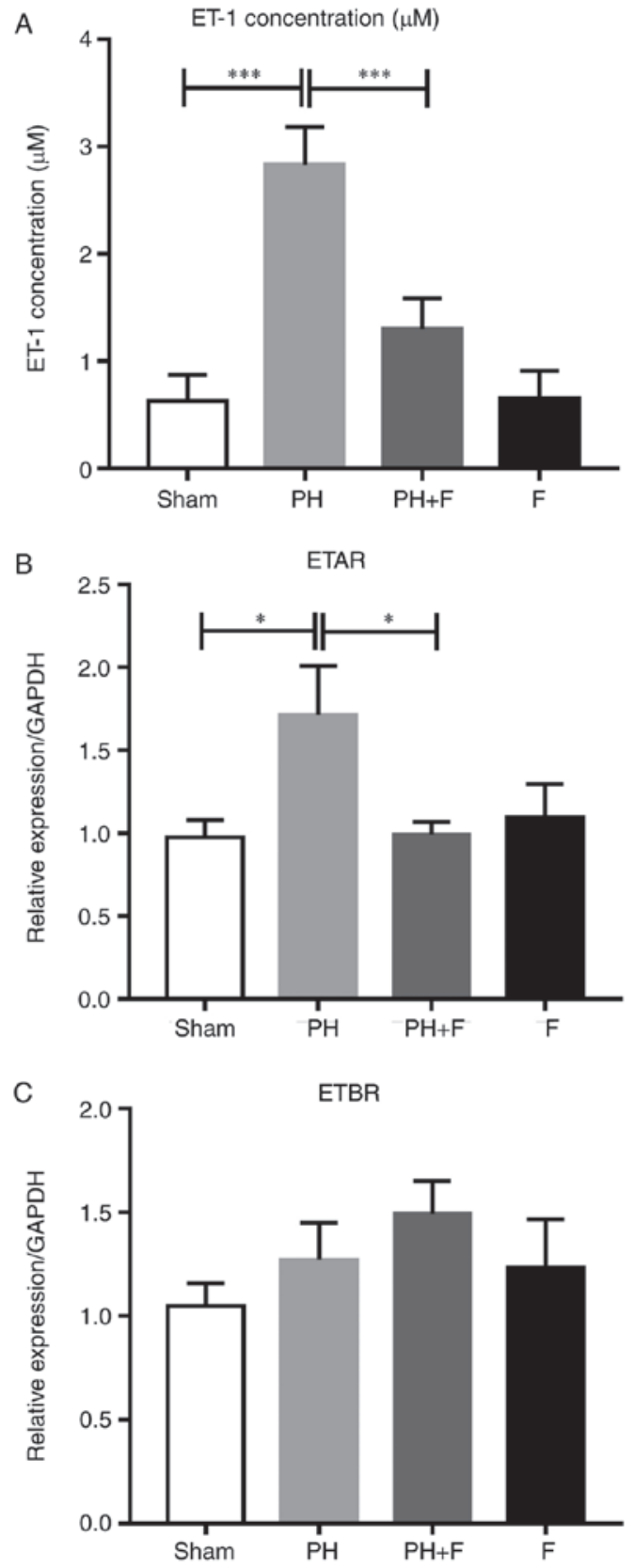

Figure 5. Effect of fasudil on the expression levels of ET-1 and ET-1 receptors in vivo. (A) Concentrations of ET-1 in the serum. (B) ETAR and (C) ETBR mRNA levels in lung tissues ( $n=9$ in Sham group, $n=14$ in $\mathrm{PH}$ group, $n=18$ in $\mathrm{PH}+\mathrm{F}$ group, and $\mathrm{n}=11$ in $\mathrm{F}$ group). ${ }^{*} \mathrm{P}<0.05$ and ${ }^{* * *} \mathrm{P}<0.001$. $\mathrm{PH}$, pulmonary hypertension; F, fasudil; ET-1, endothelin-1; ETAR, endothelin A receptor; ETBR, endothelin B receptor.

Therefore, the present study sought to determine how the administration of fasudil affects the lung endothelial cells in rats with PH-LHD. As shown in Fig. 6A, the mean number of endothelial cells in each lung arteriole increased in the $\mathrm{PH}$ group and decreased in PH-LHD rats receiving fasudil treatment. However, there was no difference in endothelial cell apoptosis in the lung arterioles (data not shown). Previously, data confirmed that activation of ROCK signaling inhibited eNOS activity and NO production (27-29). To define whether administration of fasudil was able to attenuate PH-LHD via promoting NO production in vivo, the NO concentration was detected in the serum of rats. Compared with the sham group, the NO levels were reduced in the PH group, whereas treatment with fasudil for 4 weeks restored the NO levels in the serum (Fig. 6B). Furthermore, ET-1 treatment decreased the NO production by HPMECs in vitro, whereas fasudil treatment reversed this reduction (Fig. 6C). Fig. 6D and E indicate that ET-1 also promoted the migration of HPMECs, whereas fasudil treatment inhibited this promotion.

Since the administration of fasudil markedly reduced MWT and muscularization, the study next determined whether the administration of fasudil suppressed the proliferation of HPASMCs in vitro. As shown in Fig. 6F-H, the addition of fasudil reversed the elevation in the viability and proliferation of HPASMCs that was induced by ET-1.

\section{Discussion}

There is no effective cure for the most common subset of $\mathrm{PH}$, namely PH-LHD (30). Previous studies and our previous data have demonstrated that inhibition of ROCK signaling had beneficial effects in different $\mathrm{PH}$ animal models, including decreasing the PVR (4-9). The administration of fasudil between postoperative day 29 and 42 induced PH-LHD regression (9). Furthermore, the efficacy and safety of the short-term administration of fasudil in treating human patients with $\mathrm{PH}$ has been demonstrated in clinical trials $(12-14,31)$. In the present study, fasudil ( $30 \mathrm{mg} / \mathrm{kg} /$ day) was administrated to rats commencing on day 35 after ascending aortic-banding, and treatment was maintained for 4 weeks. The treatment starting date was later, and the overall period was longer in comparison with those previously reported by Dai et al (9). The current data revealed that this late, long-term regime significantly decreased MWT and RVSP, suggesting the potential efficacy of a later and longer-term treatment with fasudil in preventing hemodynamic disorders in patients with end-stage established PH-LHD. This evidence further expands the data regarding the effective time-frame for the administration of fasudil in the treatment of PH-LHD.

PH-LHD is primarily caused by LV failure; thus, it is crucial to improve LV function and reverse the increase in PVR for patients with LV dysfunction. However, therapies using anti-PH vasodilators are associated with exacerbated LV hypertrophy in animal models subjected to HF (32), and deteriorated pathology in patients with congestive HF (33). In addition, fasudil has been demonstrated to markedly attenuate LV dysfunction and LV hypertrophy induced by partial abdominal aortic constriction (34). It has also been reported that the long-term suppression of ROCK signaling with fasudil contributes to LV geometry and dysfunction in aortic-banded rats (15), and represses the remodeling of the infarcted heart in a murine model (17). The findings of the present study suggested that hypertrophy occurred in the left and right ventricles at day 63 post-supracoronary aortic banding surgery, while LV hypertrophy was much more pronounced in comparison with RV hypertrophy. Administration of fasudil significantly attenuated the myocyte hypertrophy of both the left and right ventricles in PH-LHD rats. This evidence indicated that starting fasudil treatment at a late stage is effective in preventing ventricular dysfunction and the progression of PH-LHD.

Although there are different etiologies, patients with PH often present with similar pulmonary vascular remodeling to 

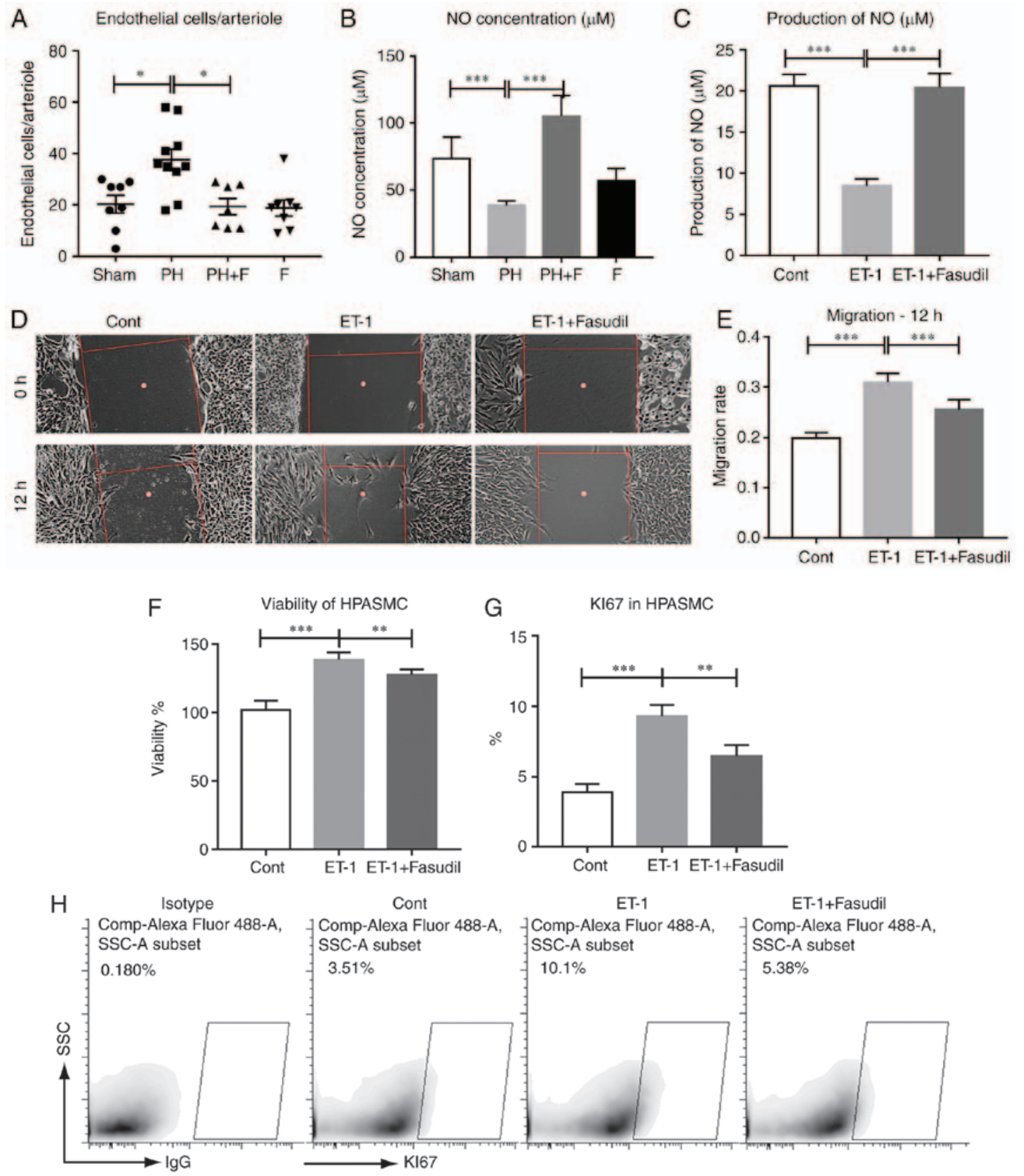

Figure 6. Fasudil treatment inhibited the proliferation of HPMECs and HPASMCs. (A) Endothelial cell number per arteriole. (B) Concentration of NO in the serum ( $\mathrm{n}=9$ in Sham group, $\mathrm{n}=14$ in PH group, $\mathrm{n}=18$ in PH+F group, and $\mathrm{n}=11$ in F group). (C) Production of NO in HPMECs with different treatments. (D) Representative figures of HPMEC migration. (E) Summarized data of the HPMEC migration rate. Representative data from four independent experiments are shown. (F) Viability of HPASMCs. (G) Summarized data of the percentage of Ki67-positive HPASMCs. (H) Representative figures of the Ki67-positive cell fraction. ${ }^{*} \mathrm{P}<0.05,{ }^{* *} \mathrm{P}<0.01$ and ${ }^{* * *} \mathrm{P}<0.001$. $\mathrm{PH}$, pulmonary hypertension; F, fasudil; HPMECs, human pulmonary microvascular endothelial cells; HPASMCs, human pulmonary artery smooth muscle cells.

those with PAH. Consistent with previous findings reporting that fasudil can attenuate high flow-induced (35) and hypoxic pulmonary vascular remodeling in rats (36), the present study demonstrated that blocking ROCK with fasudil can effectively reverse pulmonary vascular remodeling in PH-LHD rat models. Additionally, the current study results further demonstrated the effective time frame of fasudil treatment in a rat PH-LHD model. Further investigations in patients are required to verify the efficacy of long-term fasudil treatment in end-stage PH-LHD.

Recent studies have demonstrated the critical roles of $\mathrm{Rho} / \mathrm{ROCK}$ in the pathogenesis of $\mathrm{PH}(35,37,38)$. The expres- sion and activity of ROCK were identified to be markedly increased in the lungs of $\mathrm{PH}$ patients compared with the controls, and its activity level was closely associated with the severity and duration of PH (1). ROCKs are serine-threonine kinases with two known isoforms, ROCK1 (p160ROCK or ROK $\beta)$ and ROCK2 (ROK $\alpha)$. The results of the present study similarly demonstrated the enhancement of ROCK1, ROCK2 and RhoA mRNA expression levels, and of RhoA activity in a rat PH-LHD model. In addition, the protective function of fasudil against PH-LHD progression was demonstrated, which was attributed to the suppression of RhoA/ROCK activation in the lungs. Previously, Dai et al (9) reported the upregula- 
tion of ROCK 2, but not ROCK 1 in the lungs of AOB28 and AOB42 rats, and that treatment with fasudil significantly decreased the expression of ROCK 2, but not ROCK 1 . In the current study, all detections were performed at day 63 after supracoronary aortic banding surgery. The IHC results demonstrated that fasudil inhibited the upregulation of both ROCK1 and ROCK2 protein levels induced by PH-LHD in rat lungs at day 63. Furthermore, treatment with fasudil inhibited the upregulation of ROCK1 and ROCK2 levels induced by PH-LHD in pulmonary distal arteriole endothelial cells in rats. A recent study revealed that ROCK1 and ROCK 2 contribute to the profibrotic responses of endothelial cells (39). Therefore, our results suggested that the efficacy of fasudil in blunting the progression of end-stage LHD-PH in rat models may partly contribute to the inhibition of ROCK1, as well as ROCK2, in pulmonary endothelial cells.

ET-1 is highly expressed in the lung, compared with other organs (40), and the severity of $\mathrm{PH}$ is positively associated with the ET-1 level $(25,26)$. ET-1 can activate ROCK via binding to ETAR in endothelial cells (41-43). Data from the present study demonstrated that ascending aortic banding for 63 days resulted in a significant increase in the mean PAP and upregulation of ET-1 in the serum of rats, which is consistent with the observations of previous studies $(44,45)$. Treatment with fasudil reduced the expression levels of ET-1 and ETAR in the lungs of rats with PH-LHD. This indicated that blockade of ROCK signaling by fasudil may inhibit ET-1 production and activity. The observation that ET-1 can activate Rho signaling supports the hypothesis that decreased RhoA activity in the lungs of rats with PH-LHD may be attributed to a combination of direct inhibition of ROCK signaling and reduction of ET-1 expression.

Pulmonary vascular remodeling is caused primarily by endothelial cell proliferation, apoptosis and dysfunction (46). The impairment of endothelial function serves a key role in the progression of PH (47). The present study results indicated that fasudil treatment may prevent cell proliferation in small-to-moderate size pulmonary arteries in the $\mathrm{PH}$ group. Although the increase in endothelial cell apoptosis is considered to be the driving factor of PAH onset (48), the endothelial cell apoptosis levels in this rat PH-LHD model were similar to those in the sham rats, suggesting that an effect on endothelial cell apoptosis may not mediate the protective effect of fasudil. By contrast, it was also identified that treatment with ET-1 contributed to the migration of HPMECs, and the addition of fasudil inhibited this process. This is consistent with a previous study reporting that the dysfunctional angiogenesis of endothelial cells serves a critical role in the initiation and development of PAH (49). The findings of the present study support the hypothesis that fasudil can inhibit dysfunctional angiogenesis in a rat PH-LHD model.

A previous study revealed that the imbalanced release of endothelial vasoactive mediators, such as $\mathrm{NO}$, prostacyclin or ET-1, serves a key role in controlling the pulmonary vascular tone, hypertrophy and remodeling in $\mathrm{PH}$ (47). In addition, the inhibition of ROCK signaling increases eNOS expression, thus serving a protective role in the vasculature $(28,29,38)$. A later study reported that ET-1 regulates the phosphorylation state of eNOS via activating the ROCK signaling pathway (41). In the present study, it was observed that the NO levels significantly decreased in the serum of the PH group, and that the administration of fasudil upregulated the NO level. Further data confirmed that exogenous ET-1 decreased NO production in cultured HPMECs, while the inhibition of ROCK signaling by fasudil reversed this reduction. This is consistent with the recent finding that increased ET-1 levels regulate the endothelial NO production via ROCK, therefore modulating cerebral circulation (41). Previous studies revealed that fasudil treatment inhibited the proliferation of PASMCs induced by 5-hydroxytryptamine (10) or platelet-derived growth factor (50). In the current study, the results demonstrated that the addition of fasudil also prevented the elevation of viability and proliferation induced by ET-1 in HPASMCs. Therefore, fasudil exerted its role on both pulmonary endothelial cells and PASMCs.

In conclusion, the inhibition of the ROCK signaling pathway by the late, long-term administration of fasudil is sufficient to ameliorate the development of established PH-LHD. In addition, fasudil decreased the expression levels of ET-1 and ETAR, depressed the proliferation of endothelial cells in pulmonary arterioles, and promoted NO production in rats with PH-LHD. Furthermore, fasudil inhibited the migration of HPMECs and the proliferation of HPASMCs induced by ET-1. These results suggest that late, long-term treatment with fasudil may be a promising strategy to prevent and attenuate the development of PH-LHD in middle- to end-stage patients through the inhibition of the RhoA/ROCK signaling pathway.

\section{Acknowledgements}

The authors would like to thank Dr Ping Yuan from the Department of Pulmonary Function of the Shanghai Pulmonary Hospital (Shanghai, China) for hemodynamic measurements and advice on analyzing the hemodynamic data.

\section{Funding}

This study was supported by grants from the National Natural Science Foundation of China (nos. 81370434, 81670458, 81470393 and 81302545), the Shanghai Leading Talents (no. 2012053), the Innovative Project of Pudong Science and Technology (no. Pkj2013-z03), the Health Industry Project of Pudong Health Bureau of Shanghai (no. PW2013E-1) and the Program for Young Excellent Talents in Tongji University (no. 2015KJ073).

\section{Availability of data and materials}

All data generated or analyzed during this study are included in this published article, and more detailed data during the current study are available from the corresponding author on reasonable request.

\section{Authors' contributions}

RZ, JW and FL contributed equally to the present study, and participated in the research, acquisition and analysis of the data. LH, XL, QM, YJ, ZW and AY participated in data acquisition. $\mathrm{XZ}, \mathrm{JW}$ and RZ contributed to the conception and design of the study. YG, HF, XZ and ZL participated in the data analysis and interpretation. $\mathrm{XZ}$ and $\mathrm{RZ}$ participated in the article drafting, 
revising and final approval of the version to be submitted. XZ, $\mathrm{HF}$ and ZL contributed to the funding application.

\section{Ethics approval and consent to participate}

All rats used in the experiments and all study protocols were approved by the Institutional Animal Care and Use Committee of Tongji University (Shanghai, China; date of application, April 15, 2016; approval no., TJLAC-015-033).

\section{Patient consent for publication}

Not applicable.

\section{Competing interests}

The authors declare that they have no competing interests.

\section{References}

1. Do e Z, Fukumoto Y, Takaki A, Tawara S, Ohashi J, Nakano M, Tada T, Saji K, Sugimura K, Fujita H, et al: Evidence for Rho-kinase activation in patients with pulmonary arterial hypertension. Circ J 73: 1731-1739, 2009.

2. Delgado JF, Conde E, Sánchez V, López-Ríos F, Gómez-Sánchez MA, Escribano P, Sotelo T, Gómez de la Cámara A, Cortina J and de la Calzada CS: Pulmonary vascular remodeling in pulmonary hypertension due to chronic heart failure. Eur J Heart Fail 7: 1011-1016, 2005.

3. Galie N, Hoeper MM, Humbert M, Torbicki A, Vachiery JL, Barbera JA, Beghetti M, Corris P, Gaine S, Gibbs JS, et al Guidelines for the diagnosis and treatment of pulmonary hypertension: The task force for the diagnosis and treatment of pulmonary hypertension of the European Society of Cardiology (ESC) and the European Respiratory Society (ERS), endorsed by the International Society of Heart and Lung Transplantation (ISHLT). Eur Heart J 30: 2493-2537, 2009.

4. Abe K, Shimokawa H, Morikawa K, Uwatoku T, Oi K, Matsumoto Y, Hattori T, Nakashima Y, Kaibuchi K, Sueishi K and Takeshit A: Long-term treatment with a Rho-kinase inhibitor improves monocrotaline-induced fatal pulmonary hypertension in rats. Circ Res 94: 385-393, 2004.

5. Bei Y, Hua-Huy T, Duong-Quy S, Nguyen VH, Chen W, Nicco C, Batteux F and Dinh-Xuan AT: Long-term treatment with fasudil improves bleomycin-induced pulmonary fibrosis and pulmonary hypertension via inhibition of Smad2/3 phosphorylation. Pulm Pharmacol Ther 26: 635-643, 2013.

6. Elias-Al-Mamun M, Satoh K, Tanaka S, Shimizu T, Nergui S, Miyata S, Fukumoto Y and Shimokawa H: Combination therapy with fasudil and sildenafil ameliorates monocrotaline-induced pulmonary hypertension and survival in rats. Circ J 78: 967-976, 2014.

7. Mouchaers KT, Schalij I, de Boer MA, Postmus PE, van Hinsbergh VW, van Nieuw Amerongen GP, Vonk Noordegraaf A and van der Laarse WJ: Fasudil reduces monocrotaline-induced pulmonary arterial hypertension: Comparison with bosentan and sildenafil. Eur Respir J 36: 800-807, 2010.

8. Oka M, Homma N, Taraseviciene-Stewart L, Morris KG, Kraskauskas D, Burns N, Voelkel NF and McMurtry IF: Rho kinase-mediated vasoconstriction is important in severe occlusive pulmonary arterial hypertension in rats. Circ Res 100 923-929, 2007.

9. Dai ZK, Wu BN, Chen IC, Chai CY, Wu JR, Chou SH, Yeh JL, Chen IJ and Tan MS: Attenuation of pulmonary hypertension secondary to left ventricular dysfunction in the rat by Rho-kinase inhibitor fasudil. Pediatr Pulmonol 46: 45-59, 2011.

10. Raja SG: Evaluation of clinical efficacy of fasudil for the treatment of pulmonary arterial hypertension. Recent Pat Cardiovas Drug Discov 7: 100-104, 2012.

11. Guilluy C, Eddahibi S, Agard C, Guignabert C, Izikki M, Tu L, Savale L, Humbert M, Fadel E, Adnot S, et al: RhoA and Rho kinase activation in human pulmonary hypertension: Role of 5-HT signaling. Am J Respir Crit Care Med 179: 1151-1158, 2009.
12. Li F, Xia W, Yuan S and Sun R: Acute inhibition of Rho-kinase attenuates pulmonary hypertension in patients with congenital heart disease. Pediatr Cardiol 30: 363-366, 2009.

13. Kojonazarov B, Myrzaakhmatova A, Sooronbaev T, Ishizaki T and Aldashev A: Effects of fasudil in patients with high-altitude pulmonary hypertension. Eur Respir J 39: 496-498, 2012.

14. Jiang $X$, Wang YF, Zhao QH, Jiang R, Wu Y, Peng FH, Xu XQ, Wang L, He J and Jing ZC: Acute hemodynamic response of infused fasudil in patients with pulmonary arterial hypertension: A randomized, controlled, crossover study. Int J Cardiol 177: 61-65, 2014.

15. Phrommintikul A, Tran L, Kompa A, Wang B, Adrahtas A, Cantwell D, Kelly DJ and Krum H: Effects of a Rho kinase inhibitor on pressure overload induced cardiac hypertrophy and associated diastolic dysfunction. Am J Physiol Heart Circ Physiol 294: H1804-H1814, 2008.

16. Satoh S, Ueda Y, Koyanagi M, Kadokami T, Sugano M, Yoshikawa Y and Makino N: Chronic inhibition of Rho kinase blunts the process of left ventricular hypertrophy leading to cardiac contractile dysfunction in hypertension-induced heart failure. J Mol Cell Cardiol 35: 59-70, 2003.

17. Hattori T, Shimokawa H, Higashi M, Hiroki J, Mukai Y, Tsutsui H, Kaibuchi K and Takeshita A: Long-term inhibition of Rho-kinase suppresses left ventricular remodeling after myocardial infarction in mice. Circulation 109: 2234-2239, 2004.

18. Yin N, Kaestle S, Yin J, Hentschel T, Pries AR, Kuppe H and Kuebler WM: Inhaled nitric oxide versus aerosolized iloprost for the treatment of pulmonary hypertension with left heart disease. Criti Care Med 37: 980-986, 2009.

19. Yuan P, Wu WH, Gao L, Zheng ZQ, Liu D, Mei HY, Zhang ZL and Jing ZC: Oestradiol ameliorates monocrotaline pulmonary hypertension via NO, prostacyclin and endothelin-1 pathways. Eur Respir J 41: 1116-1125, 2013.

20. Fan YF, Zhang R, Jiang X, Wen L, Wu DC, Liu D, Yuan P, Wang YL and Jing ZC: The phosphodiesterase-5 inhibitor vardenafil reduces oxidative stress while reversing pulmonary arterial hypertension. Cardiovasc Res 99: 395-403, 2013.

21. Dolber PC, Beyer EC, Junker JL and Spach MS: Distribution of gap junctions in dog and rat ventricle studied with a double-label technique. J Mol Cell Cardiol 24: 1443-1457, 1992.

22. Wu C, Liu F, Zhou X, Cheng Z, Yang X, Xiao H, Chen Q and Cai K: Effect of protein kinase $\mathrm{C}$ on proliferation and apoptosis of $\mathrm{T}$ lymphocytes in idiopathic thrombocytopenic purpura children. Cell Mol Immunol 2: 197-203, 2005.

23. Livak KJ and Schmittgen TD: Analysis of relative gene expression data using real-time quantitative PCR and the 2(-Delta Delta C(T)) method. Methods 25: 402-408, 2001.

24. Hentschel T, Yin N, Riad A, Habbazettl H, Weimann J, Koster A, Tschope C, Kuppe $\mathrm{H}$ and Kuebler WM: Inhalation of the phosphodiesterase-3 inhibitor milrinone attenuates pulmonary hypertension in a rat model of congestive heart failure. Anesthesiology 106: 124-131, 2007.

25. Keller RL, Tacy TA, Hendricks-Munoz K, Xu J, Moon-Grady AJ, Neuhaus J, Moore P, Nobuhara KK, Hawgood S and Fineman JR: Congenital diaphragmatic hernia: Endothelin-1, pulmonary hypertension, and disease severity. Am J Respir Crit Care Med 182: 555-561, 2010.

26. Kobayashi H and Puri P: Plasma endothelin levels in congenital diaphragmatic hernia. J Pediatr Surg 29: 1258-1261, 1994.

27. Sugimoto M, Nakayama M, Goto TM, Amano M, Komori K and Kaibuchi K: Rho-kinase phosphorylates eNOS at threonine 495 in endothelial cells. Biochem Biophys Res Commun 361: 462-467, 2007.

28. Wolfrum S, Dendorfer A, Rikitake Y, Stalker TJ, Gong Y, Scalia R, Dominiak P and Liao JK: Inhibition of Rho-kinase leads to rapid activation of phosphatidylinositol 3-kinase/protein kinase Akt and cardiovascular protection. Arterioscler Thromb Vasc Biol 24: 1842-1847, 2004.

29. Ming XF, Viswambharan H, Barandier C, Ruffieux J, Kaibuchi K, Rusconi S and Yang Z: Rho GTPase/Rho kinase negatively regulates endothelial nitric oxide synthase phosphorylation through the inhibition of protein kinase B/Akt in human endothelial cells. Mol Cell Biol 22: 8467-8477, 2002.

30. Gerges C, Gerges M, Lang MB, Zhang Y, Jakowitsch J, Probst P, Maurer G and Lang IM: Diastolic pulmonary vascular pressure gradient: A predictor of prognosis in 'out-of-proportion' pulmonary hypertension. Chest 143: 758-766, 2013. 
31. Zhang Y and Wu S: Effects of fasudil on pulmonary hypertension in clinical practice. Pulm Pharmacol Ther 46: 54-63, 2017.

32. Oie E, Yndestad A, Robins SP, Bornerheim R, Asberg A and Attramadal $\mathrm{H}$ : Early intervention with a potent endothelin-A/endothelin-B receptor antagonist aggravates left ventricular remodeling after myocardial infarction in rats. Basic Res Cardiol 97: 239-247, 2002.

33. Kaluski E, Cotter G, Leitman M, Milo-Cotter O, Krakover R, Kobrin I, Moriconi T, Rainisio M, Caspi A, Reizin L, et al Clinical and hemodynamic effects of bosentan dose optimization in symptomatic heart failure patients with severe systolic dysfunction, associated with secondary pulmonary hypertension-a multi-center randomized study. Cardiology 109 : 273-280, 2008

34. Balakumar P and Singh M: Differential role of rho-kinase in pathological and physiological cardiac hypertrophy in rats. Pharmacology 78: 91-97, 2006.

35. Li F, Xia W, Li A, Zhao C and Sun R: Long-term inhibition of Rho kinase with fasudil attenuates high flow induced pulmonary artery remodeling in rats. Pharmacol Res 55: 64-71, 2007.

36. Sun XZ, Tian XY, Wang DW and Li J: Effects of fasudil on hypoxic pulmonary hypertension and pulmonary vascular remodeling in rats. Eur Rev Med Pharmacol Sci 18: 959-964, 2014.

37. Fukumoto Y, Matoba T, Ito A, Tanaka H, Kishi T, Hayashidani S Abe K, Takeshita A and Shimokawa H: Acute vasodilator effects of a Rho-kinase inhibitor, fasudil, in patients with severe pulmonary hypertension. Heart 91: 391-392, 2005.

38. Nunes KP, Rigsby CS and Webb RC: RhoA/Rho-kinase and vascular diseases: What is the link? Cell Mol Life Sci 67: 3823-3836, 2010.

39. Knipe RS, Probst CK, Lagares D, Franklin A, Spinney JJ, Brazee PL, Grasberger P, Zhang L, Black KE, Sakai N, et al: The Rho Kinase Isoforms ROCK1 and ROCK2 each contribute to the development of experimental pulmonary fibrosis. Am J Respir Cell Mol Biol 58: 471-481, 2018.

40. Matsumoto H, Suzuki N, Onda H and Fujino M: Abundance of endothelin-3 in rat intestine, pituitary gland and brain. Biochem Biophys Res Commun 164: 74-80, 1989.

41. Faraco G, Moraga A, Moore J, Anrather J, Pickel VM and Iadecola C: Circulating endothelin-1 alters critical mechanisms regulating cerebral microcirculation. Hypertension 62: 759-766, 2013.
42. Miao L, Dai Y and Zhang J: Mechanism of RhoA/Rho kinase activation in endothelin-1-induced contraction in rabbit basilar artery. Am J Physiol Heart Circ Physiol 283: H983-H989, 2002.

43. Ma MM, Li SY, Wang M and Guan YY: Simvastatin attenuated cerebrovascular cell proliferation in the development of hypertension through Rho/Rho-kinase pathway. J Cardiovasc Pharmacol 59: 576-582, 2012.

44. Tan MS, Chai CY, Wu JR, Yeh JL, Chen IJ, Kwan AL, Jeng AY, Yang HY, Lee MH and Dai ZK: Differential change in expression of pulmonary ET-1 and eNOS in rats after chronic left ventricular pressure overload. Exp Biol Med (Maywood) 231: 948-953, 2006.

45. Chou SH, Chai CY, Wu JR, Tan MS, Chiu CC, Chen IJ, Jeng AY, Chang CI, Kwan AL and Dai ZK: The effects of debanding on the lung expression of ET-1, eNOS, and cGMP in rats with left ventricular pressure overload. Exp Biol Med (Maywood) 231: 954-959, 2006

46. Sakao S, Tatsumi K and Voelkel NF: Endothelial cells and pulmonary arterial hypertension: Apoptosis, proliferation, interaction and transdifferentiation. Respir Res 10: 95, 2009.

47. Budhiraja R, Tuder RM and Hassoun PM: Endothelial dysfunction in pulmonary hypertension. Circulation 109: 159-165, 2004.

48. Long L, Ormiston ML, Yang X, Southwood M, Gräf S, Machado RD, Mueller M, Kinzel B, Yung LM, Wilkinson JM, et al: Selective enhancement of endothelial BMPR-II with BMP9 reverses pulmonary arterial hypertension. Nat Med 21: 777-785, 2015.

49. Tuder RM, Cool CD, Yeager M, Taraseviciene-Stewart L, Bull TM and Voelkel NF: The pathobiology of pulmonary hypertension. Endothelium. Clin Chest Med 22: 405-418, 2001.

50. Liu AJ, Ling F, Wang D, Wang Q, Lu XD and Liu YL: Fasudil inhibits platelet-derived growth factor-induced human pulmonary artery smooth muscle cell proliferation by up-regulation of p27kip(1) via the ERK signal pathway. Chin Med J (Engl) 124: 3098-3104, 2011

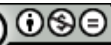

This work is licensed under a Creative Commons Attribution-NonCommercial-NoDerivatives 4.0 International (CC BY-NC-ND 4.0) License. 